\title{
Commentary: Improving donor size matching in pediatric heart transplantation-Moving beyond body weight
}

\author{
Katsuhide Maeda, MD, PhD, and John C. Dykes, MD
}

\footnotetext{
From the Departments of Cardiothoracic Surgery and Pediatrics, Stanford University School of Medicine, Stanford, Calif

Disclosures: Authors have nothing to disclose with regard to commercial support

Received for publication July 12, 2019; accepted for publication July 15, 2019; available ahead of print Aug 19 , 2019.

Address for reprints: Katsuhide Maeda, MD, PhD, Department of Cardiothoracic Surgery, Stanford University, 300 Pasteur Dr, Stanford, CA 94305 (E-mail: kmaeda@stanford.edu).

J Thorac Cardiovasc Surg 2019;158:1661-2

$0022-5223 / \$ 36.00$

Copyright (c) 2019 by The American Association for Thoracic Surgery

https://doi.org/10.1016/j.jtcvs.2019.07.026
}

This study in this issue of the Journal by Riggs and colleagues ${ }^{1}$ elucidates the wide variation in maximal acceptable donor-candidate weight ratios among pediatric heart transplant centers, illustrating the lack of any standard weight-based size assessment method. Despite the variation, there was no impact on posttransplant survival for patients at the highest donor-candidate weight ratios, despite having more traditional risk factors for poor outcomes. Furthermore, in the subgroup analysis of critically ill children, the listing strategy in the "liberal" group was beneficial, with lower waiting list mortality and similar posttransplant outcomes. These findings raise 2 important questions: What is the most accurate way to assess total cardiac volume? And what is the largest size discrepancy that will decrease waiting list morbidity and mortality without adversely affecting posttransplant outcomes?

It has become increasingly clear that body weight is an inadequate way of assessing total cardiac volume (TCV). The ideal pediatric anthropometric measurement or combination of measurements for size matching remains elusive as they rely on a number of assumptions of how body weight, height, and body surface area relate to TCV. This is problematic in a heterogenous population with heart failure in which somatic growth and heart dilation are affected to varying degrees. There have been some attempts to predict TCV in pediatrics; however, larger studies are needed to fine-tune these models. ${ }^{2}$

One promising method of assessing TCV is direct volumetric measurement by noncontrast computed tomography or magnetic resonance imaging. ${ }^{2}$ At our center, a rapid TCV assessment of the donor can be performed and compared with the TCV of the potential recipient to assess size eligibility. This type of "virtual transplant" also allows the detailed assessment of potential surgical issues, particularly in patients with congenital heart disease and ventricular assist devices. In addition, one should consider surgical options to expand recipient thoracic cavity volume including excising pericardium, dissecting the

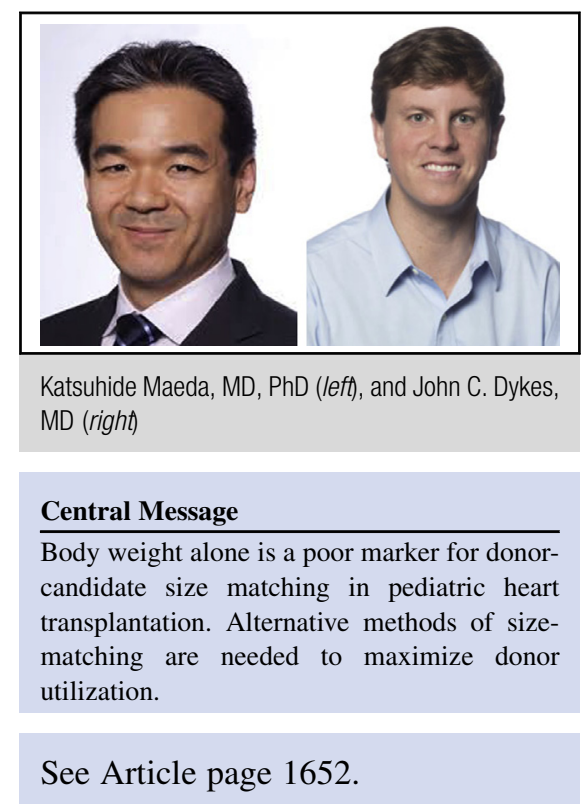

diaphragm, or repairing any chest wall deformity. We recently had a patient with severe pectus excavatum causing significant cardiac compression. In this case, we were able to accommodate a much larger heart by fixing the pectus at the time of transplant. Finally, what maximum size discrepancy is acceptable? Surgeons are sometimes hesitant to transplant an oversized heart. It is possible, however, that the hearts presumed to be "larger" by donor-candidate weight criteria are not larger by cardiac volume. Furthermore, if we consider the experience of centers that routinely accept large donors, along with the early experience of heterotopic heart transplantation, it may be possible there is a higher acceptable maximum size discrepancy. ${ }^{3,4}$ To find this ceiling, we must have an adequate way to assess TCV.

Size matching in pediatric heart transplantation remains a complicated issue, with many unanswered questions. Outcomes for waiting list survival may actually improve if centers are routinely able to consider larger donors. The effect on posttransplant outcomes is uncertain, but it is possible that the widespread use of larger donors could change posttransplant outcomes by opening up more local high-quality donors. The fact that only $42 \%$ of pediatric donor hearts were used cannot be ignored. Further studies aimed at maximizing organ utilization are needed. 


\section{References}

1. Riggs KW, Giannini CM, Szugye N, Woods J, Chin C, Moore RA, et al. Time for evidence-based, standardized donor size matching for pediatric heart transplantation. J Thorac Cardiovasc Surg. 2019;158: 1652-60.

2. Plascencia JD, Kamarianakis Y, Ryan JR, Karamlou T, Park SS, Nigro JJ, et al. Alternative methods for virtual heart transplant-size matching for pediatric heart transplantation with and without donor medical images available. Pediatr Transplant. 2018;22:e13290.
3. Kanani M, Hoskote A, Carter C, Burch M, Tsang V, Kostolny M. Increasing donor-recipient weight mismatch in pediatric orthotopic heart transplantation does not adversely affect outcome. Eur J Cardiothorac Surg. 2012;41:427-34.

4. Flécher E, Fouquet O, Ruggieri VG, Chabanne C, Lelong B, Leguerrier A. Heterotopic heart transplantation: where do we stand? Eur J Cardiothorac Surg. 2013;44: 201-6.

5. Morrison AK, Gowda C, Tumin D, Phelps CM, Hayes D, Tobias J, et al. Pediatric marginal donor heart: trends in US national use, 2005-2014. Pediatr Transplant. 2018;22:e13216. 